\title{
Gentamicin dosage in preterm and term neonates
}

\author{
B. M. ASSAEL, V. GIANNI, A. MARINI, P. PENEFF, AND F. SERENI
}

From the Departments of Pediatrics (II) and Obstetrics and Gynaecology (Division of Neonatology), Milan University Medical School, Italy

SUMMARY Pre-dose and peak serum levels of gentamicin were measured in 82 neonates (25-42 weeks' gestational age), and for comparison in 10 infants and 9 children. Dosage was $2-2.5 \mathrm{mg} / \mathrm{kg}$ twice daily for the neonates, and three times daily for infants and children.

Neonates were subdivided according to gestational age and weight. Serum levels of gentamicin were very variable in all groups. Preterm neonates of low gestational age (25-30 weeks) showed a $66 \%$ incidence of pre-dose levels exceeding $1 \mu \mathrm{g} / \mathrm{ml}$, indicating possible accumulation. In the less premature neonates this incidence was still $20-29 \%$. The level of $4 \mu \mathrm{g} / \mathrm{ml}$, the minimum concentration required to inhibit most of the bacteria sensitive to gentamicin, was reached in increasing numbers of neonates as their gestational age rose (from $30 \%$ in the 31 - to 35 -week gestational age group, to $60 \%$ at term); those small-for-gestational age had consistently lower levels. It is concluded that term neonates require dosage to be individualized and serum levels of the drug to be monitored.

Measurement of serum levels of gentamicin has led to improvements in its clinical use (Marks et al., 1971; Riley et al., 1971; Chang et al., 1975). In young children, however, comprehensive data on the subject are still lacking, and Taylor and Keane (1976) have emphasized that the regimens commonly suggested for children will provide an unacceptably low serum concentration of the drug in many. Fear of toxic effects may explain a reluctance to adopt higher dosages, though it is known that both term neonates and older infants need a higher dose per kg body weight than do adults (McCracken and Eichenwald, 1974). For preterm neonates data are scarce; excretion of the drug is slower, and a different kinetic may be involved (McCracken et al., 1971; Anderson et al., 1972). There are no studies relating the serum levels reached during gentamicin therapy with gestational age. Nor has the effect of intrauterine development been considered, i.e. whether the neonates are small or appropriate for gestational age. We here present the results of studies carried out on a group of infants of varying gestational ages.

\section{Materials and methods}

182 blood samples were taken from a group of 82 neonates (25-42 weeks of gestation) and for comparison from 10 older infants $(1 \cdot 5-8$ months $)$ and 9 children ( $2-4$ years) hospitalized in our departments. In all cases gentamicin had been indicated for

Received 18 March 1977 infection, either suspected or shown as being from gentamicin-sensitive Gram-negative bacteria. The dose was $2-2.5 \mathrm{mg} / \mathrm{kg}$ twice daily for the neonates, and three times daily for the others, injected intramuscularly according to the scheme suggested by Nelson and McCracken (1972). Serum levels were monitored starting from the third day of treatment using capillary blood from heel puncture. Gentamicin serum concentration was measured using the method of Grove and Randall (1955) with Bacillus subtilis as the test bacteria, which can estimate serum concentrations down to $0.25 \mu \mathrm{g} / \mathrm{ml}$. In all cases both the pre-dose and peak levels were measured; from our studies and from published reports (Mc Cracken and Jones, 1970; Echeverria et al., 1975) the latter is reached 30 to 60 minutes after intramuscular injection. The results were analysed by subdividing the neonates into four groups according to gestational age. The newborns designated small-for-gestational age (SGA) were those with a birthweight less than the 10th centile according to the standard of Gairdner and Pearson (1971) The remaining newborns were considered appropriate-for-gestational age (AGA). None of the subjects showed abnormalities of renal function as indicated by routine measurement of blood urea nitrogen and urine analysis.

\section{Results}

In Table 1 the pre-dose levels of gentamicin are given according to gestational age. Each of the 4 groups of 
Table 1 Pre-dose gentamicin serum concentrations in preterm and term neonates, infants, and children

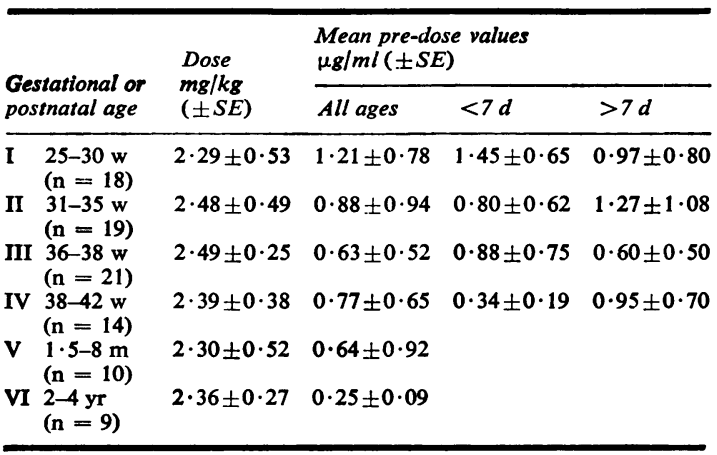

infants is further divided into those younger and older than 7 days' postnatal age. There were large differences between the levels found in preterm neonates of the same postnatal age. For comparison results are also given for a group of older infants and a group of 9 children.

Table 2 gives the percentage of cases where the

Table 2 Percentage of cases with pre-dose gentamicin concentrations $>1 \mu \mathrm{g} / \mathrm{ml}$

\begin{tabular}{llll}
\hline $\begin{array}{l}\text { Gestational or } \\
\text { postnatal age }\end{array}$ & All ages & $<7 d$ & $>7 d$ \\
\hline $25-30 \mathrm{w}$ & 66 & 71 & 50 \\
$(\mathrm{n}=18)$ & $(12 / 18)$ & $(10 / 14)$ & $(2 / 4)$ \\
$31-35 \mathrm{w}$ & 26 & 27 & 25 \\
$(\mathrm{n}=19)$ & $(5 / 19)$ & $(4 / 15)$ & $(1 / 4)$ \\
$36-38 \mathrm{w}$ & 29 & 28 & 28 \\
$(\mathrm{n}=21)$ & $(6 / 21)$ & $(2 / 7)$ & $(4 / 14)$ \\
$38-42 \mathrm{w}$ & 28 & 0 & 40 \\
$(\mathrm{n}=14)$ & $(4 / 14)$ & $(0 / 4)$ & $(4 / 10)$ \\
$1 \cdot 5-8 \mathrm{~m}$ & 20 & - & - \\
$(\mathrm{n}=10)$ & $(2 / 10)$ & - & - \\
$2-4 \mathrm{yr}$ & 0 & & \\
$(\mathrm{n}=9)$ & $(0 / 9)$ & & \\
\hline
\end{tabular}

Number of cases in parentheses.

pre-dose serum gentamicin exceeded $1 \mu \mathrm{g} / \mathrm{ml}$, this concentration being considered indicative of possible accumulation. In the most premature group this occurred in $66 \%$ of all cases, or in $71 \%$ if aged less than 7 days. In the other groups of preterm neonates the incidence of a pre-dose level over $1 \mu \mathrm{g} / \mathrm{ml}$ was between 25 and $29 \%$, while in the group of term neonates it depended on the postnatal age. For the older infants the incidence was $20 \%$, while in the older children the value was never exceeded.

Values at 30 and 60 minutes after injection are given in Table 3. No data were available for neonates of less than 35 weeks' gestational age, and only a small number of neonates were older than 7 days. None of the values are significantly different between
Table 3 Gentamicin serum concentrations (mean $\pm S E$ ) 30 and 60 minutes after intramuscular administration in preterm and term neonates, infants, and children

\begin{tabular}{llc}
\hline $\begin{array}{l}\text { Gestational or } \\
\text { postnatal age }\end{array}$ & \multicolumn{2}{c}{ Gentamicin serum concentration $(\mu \mathrm{g} / \mathrm{ml})$} \\
\cline { 2 - 3 } $31-35 \mathrm{w}$ & $30 \mathrm{~min}$ & $60 \mathrm{~min}$ \\
$36-38 \mathrm{w}$ & $3 \cdot 64 \pm 1 \cdot 62$ & $2 \cdot 82 \pm 1 \cdot 48$ \\
$38-42 \mathrm{w}$ & $4 \cdot 74 \pm 2 \cdot 05$ & $3 \cdot 58 \pm 1 \cdot 73$ \\
$1.5-8 \mathrm{~m}$ & $4 \cdot 81 \pm 2 \cdot 21$ & $4 \cdot 27 \pm 1 \cdot 52$ \\
$2-4 \mathrm{yr}$ & $4 \cdot 09 \pm 1 \cdot 80$ & $2 \cdot 99 \pm 0 \cdot 80$ \\
\hline
\end{tabular}

groups due to the large variation within each group. The concentration at $\mathbf{3 0}$ minutes was always greater than that at 60 minutes. However, as shown in Fig. 1, the percentage of cases where the peak level at 30 minutes exceeds $4 \mu \mathrm{g} / \mathrm{ml}$ tends to increase with increasing gestational age. In the older infants and in children, the levels of $4 \mu \mathrm{g} / \mathrm{ml}$ are exceeded at 30 minutes in $27 \%$ and $50 \%$ of cases, respectively.

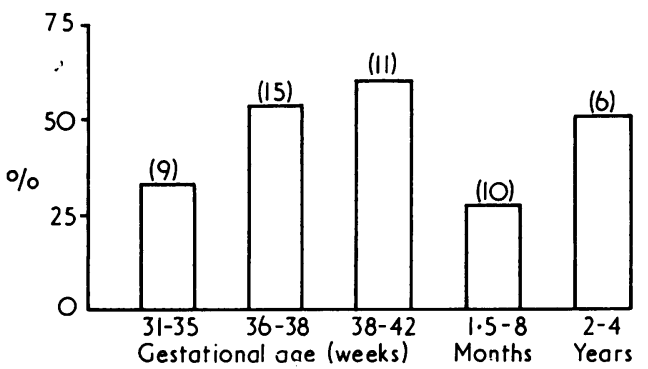

Fig. 1 Per cent of neonates, infants, and older children with gentamicin serum peak levels $>4 \mu \mathrm{g} / \mathrm{ml}$ (total number of cases in parentheses).

To analyse further the difference observed between neonates we have considered whether the condition of being AGA or SGA may influence the situation (Table 4). At both 30 and 60 minutes drug levels in the AGA infants tend to be higher than those of the SGA infants. Pre-dose levels of $1 \mu \mathrm{g} / \mathrm{ml}$ and peak levels of $4 \mu \mathrm{g} / \mathrm{ml}$ are exceeded in a larger number of AGA infants as shown in Fig. 2.

\section{Discussion}

The serum levels we observed in neonates after intramuscular injection of gentamicin were very variable and showed little relationship between the dose administered and the peak concentration (McCracken and Jones, 1970; Riley et al., 1971; 
Table 4 Gentamicin serum levels (mean $\pm S E)(\mu g / m l)$ after intramuscular administration in neonates of weight appropriate $(A G A)$ or small-for-gestational age (SGA)

\begin{tabular}{|c|c|c|c|c|}
\hline $\begin{array}{l}\text { Gestational } \\
\text { age }(w)\end{array}$ & $\begin{array}{l}\text { Weight } \\
(\mathrm{kg})\end{array}$ & Pre-dose & $30 \mathrm{~min}$ & $60 \mathrm{~min}$ \\
\hline $\begin{array}{l}A G A \\
31-35\end{array}$ & $2294 \pm 352$ & $0.96 \pm 0.89$ & $4 \cdot 56 \pm 1 \cdot 46$ & $3 \cdot 58 \pm 1 \cdot 35$ \\
\hline $36-38$ & $2809 \pm 434$ & $0.58 \pm 0.41$ & $5 \cdot 57 \pm 2 \cdot 81$ & $3 \cdot 42 \pm 2 \cdot 15$ \\
\hline $38-42$ & $3264 \pm 510$ & $0.68 \pm 0.60$ & $5 \cdot 65 \pm 2 \cdot 38$ & $4 \cdot 59 \pm 1 \cdot 49$ \\
\hline $\begin{array}{l}S G A \\
31-35\end{array}$ & $1914 \pm 394$ & $0.42 \pm 0.22$ & $2 \cdot 49 \pm 1.06$ & $1 \cdot 56 \pm 0 \cdot 47$ \\
\hline $36-38$ & $1781 \pm 536$ & $0.77 \pm 0.72$ & $4 \cdot 55 \pm 1 \cdot 92$ & $3 \cdot 63 \pm 1 \cdot 68$ \\
\hline $38-42$ & $2255 \pm 310$ & $0.45 \pm 0.29$ & $3 \cdot 41 \pm 1 \cdot 19$ & $3 \cdot 38 \pm 1 \cdot 62$ \\
\hline
\end{tabular}

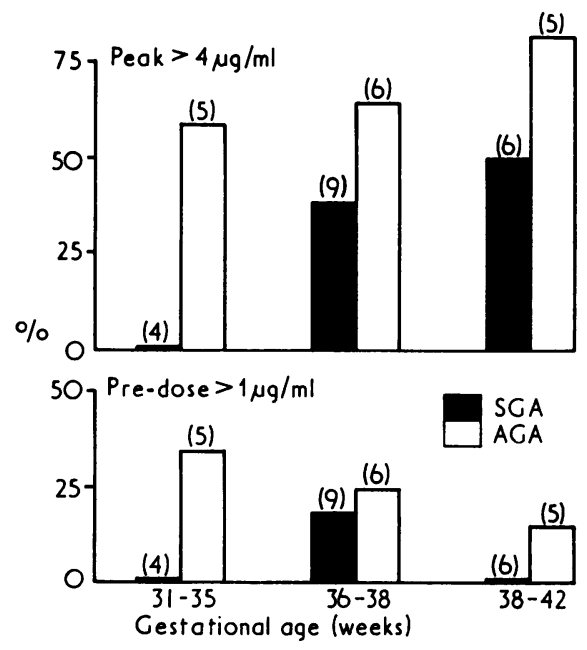

Fig. 2 Percentage of neonates with pre-dose gentamicin concentrations $>1 \mu \mathrm{g} / \mathrm{ml}$ and peak concentrations $>4 \mu \mathrm{g} / \mathrm{ml}$ (total number of cases in parentheses).

Klein et al., 1971; Rosdahl and Andersen, 1973). A peak serum value $>4 \mu \mathrm{g} / \mathrm{ml}$ is suggested as an appropriate minimum inhibitory concentration for those gentamicin-sensitive bacteria which are commonly responsible for neonatal infections, but this concentration was often not obtained.

There are no studies on the relationship between toxicity and gentamicin levels in the neonate. In adults Mawer et al. (1973) have correlated ototoxicity with drug levels. McCracken et al. (1971) have recommended lengthening the time interval between doses when the pre-dose values exceed $1 \mu \mathrm{g} / \mathrm{ml}$, and suggest therefore a regimen of $2.5 \mathrm{mg} / \mathrm{kg}$ every 12 hours for infants less than a week old. Although many of our patients failed to reach the concentra- tion of $4 \mu \mathrm{g} / \mathrm{ml}$, the same therapeutic regimen may easily lead to pre-dose levels $>1 \mu \mathrm{g} / \mathrm{ml}$.

The differences we found in gentamicin serum concentrations between AGA and SGA infants may depend upon the following considerations. Gentamicin is a water soluble molecule which is distributed almost exclusively in the extracellular fluids and is eliminated mainly by glomerular filtration. Relevant therefore is the decrease in extracellular fluid and the increase of glomerular filtration with gestational age. For the same gestational age AGA and SGA infants have comparable renal function (Siegel and Oh, 1976), while SGA infants have, proportionally, a larger extracellular fluid compartment (Cassady, 1970). The fact that we have consistently observed lower serum gentamicin concentrations in SGA neonates than in the AGA group at the same postnatal age may thus be attributed to a larger volume of distribution, renal function being approximately the same.

We conclude that the usual regimen of gentamicin therapy for preterm and term neonates is inadequate. In preterm neonates of less than 31 weeks' gestational age the interval between each gentamicin injection should be longer than 12 hours. On the other hand, SGA neonates may need single doses higher than $2.5 \mathrm{mg} / \mathrm{kg}$. It is highly desirable to monitor serum levels of the drug and to individualize therapy.

This work was supported by Consiglio Nazionale delle Ricerche, Rome; Programme of Preventive Medicine sub project no. 76.00631.83.

\section{References}

Andersen, J. B., Rosdahl, N., and Vejlsgaard, R. (1972). Aspects of pharmacology of gentamicin in newborn infants. Acta Paediatrica Scandinavica, 61, 343-349.

Cassady, G. (1970). Body composition in intrauterine growth retardation. Pediatric Clinics of North America, 17, 79-99.

Chang, M. J., Escobedo, M., Anderson, D. C., Hillman, L., and Feigin, R. D. (1975). Kanamycin and gentamicin treatment of neonatal sepsis and meningitis. Pediatrics, 56, 695-699.

Echeverria, P., Siber, G. R., Paisley, J., Smith, A. L., Smith, D. H., and Jaffe, N. (1975). Age-dependent dose response to gentamicin. Journal of Pediatrics, 87, 805-808.

Gairdner, D., and Pearson, J. (1971). A growth chart for premature and other infants. Archives of Disease in Childhood, 46, 783-787.

Grove, D. C., and Randall, W. A. (1955). Assay Methods of Antibiotics, p. 34. Medical Encyclopaedia, New York.

Klein, J. O., Herschel, M., Therakan, R. M., and Ingall, D. (1971). Gentamicin in serious neonatal infections: absorption and clinical results in 25 cases. Journal of Infectious Diseases, 124, Suppl., 224S-231S.

McCracken G. H., Jr., and Eichenwald, H. F. (1974). Antimicrobial therapy, therapeutic recommendations and a review of the newer drugs. Journal of Pediatrics, 85, 451456. 
McCracken, G. H., Jr., and Jones, L. G. (1970). Gentamicin in the neonatal period. American Journal of Diseases of Children, 120, 524-533.

McCracken, G. H., Jr., West, N. R., and Horton, L. J. (1971). Urinary excretion of gentamicin in the neonatal period. Journal of Infectious Diseases, 123, 257-262.

Marks, M. I., Prentice, R., Swarson. R., Cotton, E. K., and Eickhoff, T. C. (1971). Carbenicillin and gentamicin: pharmacologic studies in patients with cystic fibrosis and pseudomonas pulmonary infections. Journal of Pediatrics, 79, 822-828.

Mawer, G. E., Ahmad, R., Dobbs, S. M., McGough, J. G., Lucas, S. B., and Tooth, J. A. (1974). Prescribing aids for gentamicin. British Journal of Clinical Pharmacology, 1, 45-50.

Nelson, J. D., and McCracken, G. H., Jr. (1972). The current status of gentamicin for the neonate and young infant. American Journal of Diseases of Children, 124, 13-14.
Riley, H. D., Jr., Rubio, T., Hinz, W., Nunnery, A. W., and Englund, J. (1971). Clinical and laboratory evaluation of gentamicin in infants and children. Journal of Infectious Diseases, 124, Suppl., 236S-246S.

Rosdahl, N., and Andersen, J. B. (1973). Aspects of the pharmacology of gentamicin during the neonatal period. Acta Pathologica et Microbiologica Scandinavica, Section B, Suppl. 241, 119-123.

Siegel, S. R., and Oh, W. (1976). Renal function as a marker of human fetal maturation. Acta Paediatrica Scandinavica, $65,481-485$.

Taylor, H., and Keane, C. (1976). Gentamicin dosage in children. Archives of Disease in Childhood, 51, 369-372.

Correspondence to Dr. B. M. Assael, Clinica Pediatrica $11^{\circ}$ dell'Università Statale, Via della Commenda 9, Milano, Italy.

The following articles will appear in future issues of this journal:

Annotation: Measles and rubella vaccines. J. A. Dudgeon.

Organ mercury levels in infants with omphaloceles treated with organic mercurial antiseptic. D. C. Fagan, J. S. Pritchard, T. W. Clarkson, and M. R. Greenwood.

Rifampicin therapy in shigellosis in infancy. Y. Naveh, P. Strahovsky, and A. Friedman.

Mannosidosis: clinical and biochemical study. P. J. Milla, I. E. Black, A. D. Patrick, K. Hugh-Jones, and $V$. Oberholzer.

Diagnosis of classical galactosaemia. A. M. Monk, A. J. H. Mitchell, D. W. A. Milligan, and J. B. Holton. Concurrence of Graves's disease and Hashimoto's thyroiditis. T. Sato, I. Takata, T. Taketani, K. Saida, and H. Nakajima.

Congenital renal abnormalities in the Laurence-Moon-Biedl syndrome. $N$. H. Bluett, C. Chantler, J. D. Singer, and H. A. Saxton.

Acute pancreatitis as a complication of anaphylactoid (Henoch-Schönlein) purpura. J. A. McV. Garner. 